\title{
The influence of moisture content on coal deformation and coal permeability during coalbed methane (CBM) production in wet reservoirs
}

\author{
Akash Talapatra $^{1} \cdot$ Md. Mostafijul Karim ${ }^{1}$
}

Received: 3 January 2020 / Accepted: 7 April 2020 / Published online: 18 April 2020

(c) The Author(s) 2020

\begin{abstract}
Moisture adsorption in the coal seams affects the gas adsorption capacity and can alter the coal deformation and permeability criteria of the coal seam. The effect of dynamic loss of moisture content, both on moisture and gas sorption-induced coal swelling/shrinkage strains, during the coalbed methane (CBM) production, is crucial. This study investigates the interactions among coal matrix, absorbed gas, and moisture content, based on the coal swelling/shrinkage strains and gas adsorption decay criteria. Consequently, a mathematical model of the coal deformation is developed for the proper evaluation of the moisture effect. For developing the model, this paper considers the standard gas flow and moisture loss equations to assess the volumetric content, equilibrium pressure, and density of the moisture. Finally, it comprehensively analyzes the sensitive factors and effects of elemental parameters of moisture content on coal deformation and coal permeability. The results show that moisture content at adsorbed state significantly changes the coal swelling/shrinkage strain and that distorted swelling and shrinkage characteristics can promote the permeability alternation in wet coal reservoirs. Moreover, the intermolecular attraction between the coal structure and the moisture content has a significant effect on methane adsorption/desorptioninduced deformation in coal structure. This study also designs the coal deformation strains as a function of moisture content by the Langmuir type model and evaluates the hysteresis rate between the swelling and shrinkage characteristics. The findings of this paper can characterize a wet coal reserve for CBM production and anticipate future production under different operating conditions.
\end{abstract}

Keywords Coal deformation · Moisture adsorption/desorption $\cdot$ Gas adsorption/desorption $\cdot$ Coal permeability $\cdot$ Coal swelling/shrinkage

\section{List of symbols}

$\varepsilon \quad$ Elements of strain tensor

$\sigma \quad$ Elements of total positive strain tensor

$u \quad$ Elements of displacement

$f \quad$ Elements of body force along the one direction

$G \quad$ Shear modulus $=E / 2 /(1+v)$

$K \quad$ Bulk modulus $=E / 3 /(1-2 v)$

$E \quad$ Young' modulus

$\nu \quad$ Poisson's ratio

$\delta \quad$ Kronecker delta

$\alpha \quad$ Biot's coefficient

Akash Talapatra

talapatraakash@gmail.com

1 Department of Petroleum and Mining Engineering, Chittagong University of Engineering \& Technology, Chittagong, Bangladesh
$K_{\mathrm{s}} \quad$ Bulk modulus of coal particles $(\mathrm{MPa})$

$\varepsilon_{\mathrm{v}} \quad$ Volumetric strain of coal

$\varepsilon_{\mathrm{s}} \quad$ Gas sorption-induced volumetric coal strain

$\varepsilon_{\theta} \quad$ Moisture sorption-induced volumetric coal strain

$P \quad$ Equilibrium pressure, $\mathrm{MPa}$

$\sigma_{\mathrm{m}} \quad$ Mean compressive stress

$\alpha_{\text {sg }} \quad$ Sorption-induced volumetric strain coefficient

$\lambda \quad$ Adsorption decay coefficient

$\theta \quad$ Volumetric content of moisture

$V_{1} \quad$ Volume constant from Langmuir model

$P_{1} \quad$ Pressure constant from Langmuir model

$m \quad$ Gas mass content $\left(\mathrm{kg} / \mathrm{m}^{3}\right)$

$\rho_{\mathrm{g}} \quad$ Density of gas $\left(\mathrm{kg} / \mathrm{m}^{3}\right)$

$v_{\mathrm{g}} \quad$ Velocity vector from Darcy's law $(\mathrm{m} / \mathrm{s})$

$Q_{\text {s }} \quad$ Gas injection through the production well $(\mathrm{kg} /$ $\mathrm{m}^{3} \mathrm{~s}^{-1}$ )

$\rho_{\text {ga }} \quad$ Density of gas $\left(\mathrm{kg} / \mathrm{m}^{3}\right)$ (at standard conditions)

$\rho_{\mathrm{c}} \quad$ Density of coal $\left(\mathrm{kg} / \mathrm{m}^{3}\right)$ 
$\varphi \quad$ Coal porosity

$T_{\mathrm{a}} \quad$ Temperature (K) (at standard conditions)

$\rho_{\mathrm{v}} \quad$ Density of water vapor $\left(\mathrm{kg} / \mathrm{m}^{3}\right)$

$T_{\mathrm{a}} \quad$ Atmospheric temperature)K) (at standard conditions)

$P_{\text {a }} \quad$ Atmospheric pressure (MPa) (at standard conditions)

$\mu \quad$ Viscosity of the gas at dynamic phase (Pa s)

$k \quad$ Coal permeability $\left(\mathrm{m}^{2}\right)$

$w \quad$ Mass of moisture content $\mathrm{kg} / \mathrm{m}^{3}$ )

$\rho_{\mathrm{m}} \quad$ Density of flowing moisture $\left(\mathrm{kg} / \mathrm{m}^{3} \mathrm{~s}^{-1}\right)$

$q_{\mathrm{g}} \quad$ Convective velocity factor $(\mathrm{m} / \mathrm{s})$

$Q_{\text {w }} \quad$ Source of moisture vapor $\left(\mathrm{kg} / \mathrm{m}^{3}\right)$

$\rho_{1} \quad$ Density of water (at liquid phase) $\left(\mathrm{kg} / \mathrm{m}^{3}\right)$

$\rho_{\mathrm{v} 0} \quad$ Preliminary density of saturate water vapor content $\left(\mathrm{kg} / \mathrm{m}^{3}\right)$

RH Dimension of relative humidity

$n \quad$ Special constant for material

$k_{\theta} \quad$ A factor defines water evaporation

$\omega$ Hysteresis rate

$\varepsilon_{\text {sd }} \quad$ Total coal swelling deformation

$\varepsilon_{\mathrm{a}} \quad$ Adsorption-induced coal deformation

$\varepsilon_{\mathrm{d}} \quad$ Desorption-induced coal deformation

$\varepsilon_{\mathrm{m}} \quad$ Deformation of coal strain by moisture sorption

$\varepsilon_{\mathrm{Lm}}$ Maximum deformation of coal strain by moisture sorption

$m_{\mathrm{L}} \quad$ Constant of moisture sorption-induced strain from Langmuir model

$m \quad$ Equilibrium moisture content in volumetric percentage

$\varepsilon_{\mathrm{s}} \quad$ Maximum value of gas sorption-induced coal deformation

$\varepsilon_{\mathrm{L}} \quad$ Maximum deformation of coal strain by gas sorption

$P_{\varepsilon} \quad$ Langmuir deformation constant

$V_{\mathrm{w}} \quad$ Adsorbed moisture content on wet seam

$V_{\mathrm{d}} \quad$ Adsorbed moisture content on dry seam

$\sigma \quad$ Effective stress in horizontal direction

$\sigma_{0} \quad$ Effective stress at initial reservoir pressure

$c_{\mathrm{f}} \quad$ Compressibility of cleat volumetric content

$k_{\mathrm{f}} \quad$ Cleat permeability

\section{Introduction}

Coalbed methane (CBM) has now made itself one of the most potential uonventional gas sources from the state being considered as a source of creating unexpected hazards in coalmine fields. Generally, the coal seams are fractured components, which have a dual-porosity media, consisting of a fracture network and coal matrix. Naturally, free water involves with CBM production in the fracture network, where moisture vapor adsorbs in the coal matrix (Mazzotti et al. 2009; Li and Fang 2014; Cui et al. 2007).
The dewatering process occurs preferentially for increasing the gas recovery from the coal gas reservoirs. Hence, the dewatering process is firstly involved with saturated water flow from the fracture, followed by two-phase flows at the time of coal seam gas recovery (Oudinot et al. 2011; Pan and Connell 2007). In wet gas reservoirs, a small amount of water content is possible to be the water-vapor phase during gas production. However, in situ dry gas reservoirs, it is not convenient to increase gas recovery without employing any external support. That is why, a hydro-fracturing technique is used to inject additional water to moisten the coal seams (Yamaguchi et al. 2006). So, it is necessary to investigate the effects of moisture content on the components of wet coal seams during gas production. Moisture content keeps a dominant role in the competition between methane and moisture to hold the adsorption site since the gas adsorption capacity depends on both of these contents. It is found that the adsorption capacity of methane can increase by $35-40 \%$ if it is stored in a humid environment for 1 year (Crosdale et al. 2008). Moisture content can affect the gas adsorption capacity within the range of critical content, and additional moisture would not be able to influence the gas adsorption beyond this content anymore (Shao et al. 2012; Masoudian et al. 2013; White et al. 2005). The influence of moisture content on the gas adsorption capacity significantly depends on the rank of the coal. Naturally, the low rank of coal is affected by moisture sorption greatly compared with the high rank of coal (Day et al. 2008). Based on the evaluation of these series of phenomena, different researchers suggested different principles to describe their experimental results. Jamison and Kroth (1958) designed a model to interpret the linear relationship between the moisture content and its effect on the gas adsorption capacity. Crosdale et al. (2008) have built a power-law connection to the gas adsorption capacity upon the characteristics of the low rank of coal found from Huntly coalfield in New Zealand. Besides, he has observed that the improvement of coal rank could linearly enhance the adsorption capacity of the methane. Moreover, the exponential decay coefficient can also describe the distinct effects of moisture content on methane adsorption both in low- and high-rank coals separately (Palmer and Mansoori 1998).

Whatever it is moisture adsorption or desorption, both can affect the coal swelling or shrinkage strain followed by the coal permeability and affect the suitability of CBM production from wet reservoirs. Coal swelling strain indeed depends on the coal ranks as different qualities of coal have different types of ability to swell; still, some types of coal are found there, which have no differences in their anisotropic swelling ability both in dry and wet conditions (Scott 2002; Bae and Bhatia 2006). Moisture adsorption/desorption-induced volumetric deformation is linearly correlated with the existence of moisture content on the related pore 
spaces. Evans and Allardice (1978)have a prediction upon his experiment that the porosity and mass content of related coal are reduced and contracted, respectively, if moisture loss increases continuously from that coal. Chen et al. (2010) have interpreted the moisture content-induced coal swelling strain by applying a Langmuir isotherm model with two constants. Pan and Connell (2012) have designed a model to explain the coal swelling strain based on the loss of moisture content and stated that according to the assumptions of multilayer moisture adsorption, only the first layer of adsorbed particles was able to alter the surface energy. The model fundamentally has been designed for describing the feasibility study of CBM production on Mount Arthur coalfield and latterly got great validation by the experimental data. Table 1 shows a summary of the critical analyses on some of the models available in the existing literature.

Although multiple theories have been proposed to analyze the influence of moisture adsorption on coal gas interactions, still there is found a lack of studies in designing an approach that can help to build out a fully cross-coupled model of coal gas-moisture relationships in wet coal seams. In previous studies, moisture content was considered as a limiting factor when the reservoir was stimulated for gas production (Pini et al. 2009; Chen et al. 2010; Vishal et al. 2013). However, the dynamic moisture loss has a vital impact on methane gas production from wet reservoirs (Perera and Ranjith 2015). This study proposes a mathematical model of moisture content loss in a coal seam due to coal gas interactions, using the coal deformation criteria and gas flow equations. After that, it has discussed the evolution of that moisture effect on coal permeability and its application in gas transport through a porous medium. Moisture sorption that initiates coal shrinkage and the gas adsorption-decay coefficient is used for explaining the chain reactions for physical interactions between coal gas and moisture. The study reveals the evolution of coal deformation strain, followed by describing the influence of moisture content on coal permeability through porous media in wet reservoirs. These models are made equally relevant for both circumstances under moisture sorption and gas sorption. As the models are considered with both mass transfer and mechanical equilibrium equations, these analyses are instrumental in working under dynamic conditions. This paper will help the researchers to understand the complex mechanism of coal gas-moisture interaction in wet coal reservoirs without creating any barrier in dynamic situations. It can expect that this study will contribute significantly to the field of CBM gas production under suitable environmental conditions.

\section{The physical structure of coal and the occurrence of moisture}

The flow processes and transport phenomena of methane gas in coal seams are considered very tangled, due to the great heterogeneous and complex variation of coal seams (Pini et al. 2011; Pan et al. 2017). Generally, the coal seam is considered as a solid formation with uniformly distributed fractures. Most of the time, methane adsorption takes place within the large internal micropores matrix area. From Fig. 1, it has been shown that connectivity in coal seam and distributions within the micropores are not literally uniform, but disconnected closed micropores and interconnected open

Table 1 Critical analysis of the previous models

\begin{tabular}{|c|c|c|c|}
\hline Refernces & Criteria & Contribution & Limitations \\
\hline Jamison and Kroth (1958) & $\begin{array}{l}\text { a. Single-phase flow } \\
\text { b. Appropriate for laminar flow }\end{array}$ & $\begin{array}{l}\text { Describe the linear relationship } \\
\text { between the moisture content } \\
\text { and its effect on gas adsorption } \\
\text { capacity }\end{array}$ & $\begin{array}{l}\text { No chemical reaction between fluid } \\
\text { and coal is considered }\end{array}$ \\
\hline Evans and Allardice (1978) & $\begin{array}{l}\text { a. Linear, isotropic and homogene- } \\
\text { ous porous media } \\
\text { b. One-dimensional fractional dif- } \\
\text { fusive equation }\end{array}$ & $\begin{array}{l}\text { Predict the reduction of poros- } \\
\text { ity with the increase in moisture } \\
\text { content }\end{array}$ & $\begin{array}{l}\text { No correlation between coal defor- } \\
\text { mation and moisture content is } \\
\text { investigated }\end{array}$ \\
\hline Bustin et al. (2008) & $\begin{array}{l}\text { a. Effective pore space is the domi- } \\
\text { nant parameter } \\
\text { b. The electro-kinetic effect is } \\
\text { considered }\end{array}$ & $\begin{array}{l}\text { Investigate the effect of intercon- } \\
\text { nected micropores on gas adsorp- } \\
\text { tion capacity }\end{array}$ & $\begin{array}{l}\text { No flow condition at the right bound- } \\
\text { ary }\end{array}$ \\
\hline Crosdale et al. (2008) & $\begin{array}{l}\text { a. Suitable to low rank of coal } \\
\text { b. A homogeneous and linear porous } \\
\text { medium }\end{array}$ & $\begin{array}{l}\text { Build a power-law relationship } \\
\text { between gas adsorption capacity } \\
\text { and coal }\end{array}$ & $\begin{array}{l}\text { Not appropriate for intermediate and } \\
\text { high ranks of coal }\end{array}$ \\
\hline Chen et al. (2010) & $\begin{array}{l}\text { a. Constant fluid and rock properties } \\
\text { b. Multiphase flow }\end{array}$ & $\begin{array}{l}\text { Match the moisture sorption initiated } \\
\text { coal deformation with the Lang- } \\
\text { muir model }\end{array}$ & Darcy effect is not included \\
\hline Pan and Connell (2012) & $\begin{array}{l}\text { a. Incompressible and viscous fluid } \\
\text { b. Single-phase flow }\end{array}$ & $\begin{array}{l}\text { Explain the coal deformation under } \\
\text { multilayer moisture adsorption }\end{array}$ & $\begin{array}{l}\text { The porosity of the medium is not } \\
\text { considered }\end{array}$ \\
\hline
\end{tabular}




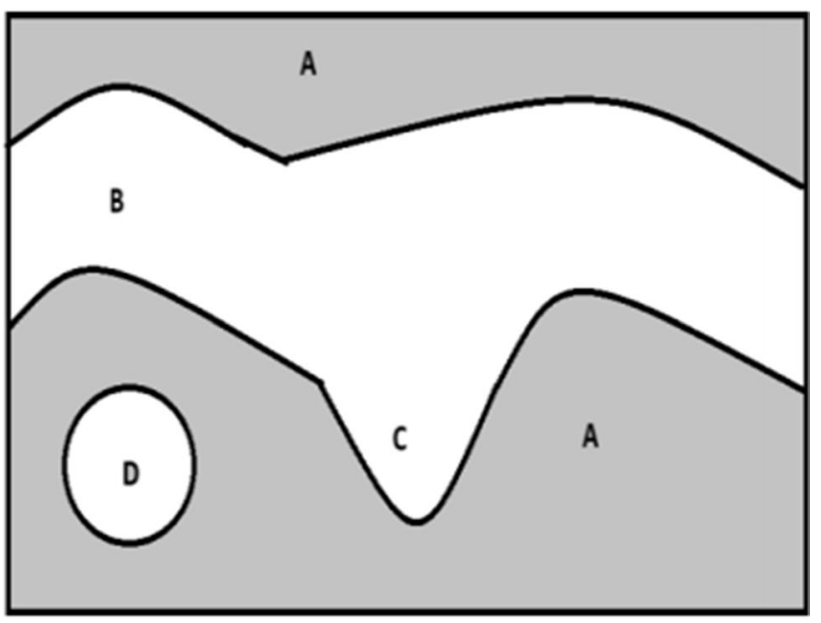

Fig. 1 Distribution of pore structure. (A $\rightarrow$ coal matrix, B $\rightarrow$ crack, C $\rightarrow$ open micropores, and $\mathrm{D} \rightarrow$ closed micropores)

micropores are still existed. The spatial extension between the open interconnected micropores has been being named as effective pore space where liquid and gas can flow in and out, while the different scenarios occur in the closed micropores. Regular methods use only the effective pore space (interconnected micropores), where this property is the most dominant parameter for determining the adsorption capacity (Gray 1987; Bustin et al. 2008; Durucan and Shi 2009).

Depending on prevailing conditions or states, there are usually found two types of moisture in coal seams. One is called free moisture, and the other is known as combined moisture. Free type of moisture comprises inner and outer layers of moisture. The inner layer moisture distributes uniformly in the existing coal void spaces or capillary spaces being as an adsorbed state on the matrix of the coal particles and diameters lower than $10^{-7} \mathrm{~m}$ (Shi and Durucan 2004). This type of moisture generally does not free away at room temperature and assembles with coal both in chemically and physically. Outer moisture adheres to the outer surface of the coal seams, and the diameters of large pores are higher than $10^{-7} \mathrm{~m}$. This part of moisture consisted depending on the outer conditions of the coal particles and their sizes. This moisture does not have any relationship directly with the quality of coal particles and combines mechanically with the coal matrix (Smith and Williams 1984).

However, the amount of moisture in the coal seam is proportional to the existence of small size capillaries and the inner coal surface area. Generally, the reason behind the increases of gas adsorption capacity is the increases of inner vapor pressure in the coal seam as the inherent moisture remained there in gaseous state.

Practically, the coal reservoir is less saturated with gas and moisture and is profoundly saturated by liquid moisture. In other words, it can say that inner and outer parts of moisture occur jointly in coal. For that reason, in this article, it is considered greater realistic to evaluate the influences of free moisture on the coal deformation during methane adsorption/desorption.

\section{Model development}

The model development process uses the fundamental equation of solid coal deformation, the gas flow, and the dynamic moisture loss, which are following the basic principle of mass conservation and the mechanical equilibrium. The following assumptions are made to develop the model:

- Coal in solid form is elastic continuum medium, homogeneous, and isotropic.

- Modulus of elasticity and Poisson's ratio in coal are constants.

- Gas flow behavior must follow the Darcy's law along with the constant viscosity of gas remained in pores.

- In wet reservoirs, moisture losses mostly in the state of vapor flow.

- Though moisture usually distributes uniformly in the coal seams, the moisture content that finds from the pore spaces in the adsorbed state is considered.

\section{Coal deformation equation}

Gas sorption with moisture content and pore pressure act as additional bodies to define the coal deformation for a linear pro-elastic media. The relationship between the displacement and the linear strain is expressed as follows (Gilman and Beckie 2000):

$\varepsilon_{i j}=\frac{1}{2}\left(u_{i, j}+u_{j, i}\right)$,

where the equilibrium is:

$\sigma_{i j}+f_{i}=0$.

The fundamental relation of the coal deformation, equilibrium pressure, and volumetric strain is (Cui and Bustin 2005):

$\varepsilon_{i j}=\frac{1}{2 G} \sigma_{i j}-\left(\frac{1}{2 G}-\frac{1}{9 K}\right) \sigma_{k k} \delta_{i j}+\frac{\alpha P}{3 K} \delta_{i j}+\frac{\varepsilon_{\mathrm{s}}}{3} \delta_{i j}+\frac{\varepsilon_{\theta}}{3} \delta_{i j}$.

T volumetric strain can be defined as:

$\varepsilon_{\mathrm{v}}=-\frac{1}{K}\left(\sigma_{\mathrm{m}}-\alpha P\right)+\varepsilon_{\mathrm{s}}+\varepsilon_{\theta}$.

Therefore, the governing equation for defining the coal deformation becomes:

$G u_{i, k k}+\frac{G}{1-2 v} u_{k, k i}-\alpha P_{i}-K \varepsilon_{\theta, i}-K \varepsilon_{\mathrm{s}, i}+F_{i}=0$. 
The gas sorption-induced volumetric coal strain is expressed by using Langmuir mel:

$\varepsilon_{\mathrm{s}}=\alpha_{\mathrm{sg}} \frac{V_{1} P}{P_{1}+P} \exp (-\lambda \theta)$,

where $\alpha_{\mathrm{sg}}=$ sorption-induced volumetric strain coefficient. e volumetric content for moisture $(\theta)$ and gas pressure $(P)$ can be determined from the gas flow and moisture loss equations.

\section{Gas flow equation}

The continuity equation for the gas flow in the coal seam is (Schepers et al. 2011):

$\frac{\partial m}{\partial t}+\nabla \cdot\left(\rho_{\mathrm{g}} v_{\mathrm{g}}\right)=Q_{\mathrm{s}}$

The gas mass content is:

$m=\varphi \rho_{\mathrm{g}}+\rho_{\mathrm{ga}} \rho_{\mathrm{c}} V_{\mathrm{s}}=\varphi \rho_{\mathrm{g}}+\rho_{\mathrm{ga}} \rho_{\mathrm{c}} \frac{V_{1} P}{P_{1}+P} \exp (-\lambda \theta)$.

After neglecting the partial water vapor pressure in ideal gas pressure, the gas density for ideal conditions can be described as follows (Wang et al. 2014):

$\rho_{\mathrm{g}}=\rho_{\mathrm{v}}+\frac{T_{\mathrm{a}} P}{T P_{\mathrm{a}}} \rho_{\mathrm{ga}} \approx \frac{T_{\mathrm{a}} P}{T P_{\mathrm{a}}} \rho_{\mathrm{ga}}$.

Dcy's law for the gas flow through fracture network in free phase is

$v_{\mathrm{g}}=-\frac{k}{\mu} \nabla P$.

Therefore, the continuity equation [Eq. (7)] becomes:

$$
\begin{aligned}
& {\left[\frac{\alpha \rho_{\mathrm{g}}}{K_{\mathrm{s}}}+\frac{T_{\mathrm{a}} \rho_{\mathrm{g}} \varphi}{T P_{\mathrm{a}}}+\frac{V_{\mathrm{l}} P_{1}\left(\rho_{\mathrm{g}} \rho_{\mathrm{c}}-\alpha \alpha_{\mathrm{sg}} \rho_{\mathrm{g}}\right) \exp (-\lambda \theta)}{\left(P_{1}+P\right)^{2}}\right] \frac{\partial p}{\partial t}} \\
& -\left[\rho_{\mathrm{g}}+\frac{V_{1} \lambda P\left(\rho_{\mathrm{g}} \rho_{\mathrm{c}}-\alpha \alpha_{\mathrm{sg}} \rho_{\mathrm{g}}\right) \exp (-\lambda \theta)}{\left(P_{1}+P\right)^{2}}\right] \frac{\partial \theta}{\partial t} \\
& +\nabla \cdot\left[-\frac{P k}{\mu} \cdot \nabla P\right]+\alpha \rho_{\mathrm{g}} \frac{\partial \varepsilon_{\mathrm{v}}}{\partial t}=Q_{\mathrm{s}} .
\end{aligned}
$$

Now, we get the form to define the gas flow through a coal seam as

$$
\begin{aligned}
& {\left[\frac{\alpha \rho_{\mathrm{g}}\left(1+\alpha K_{\mathrm{s}}\right)}{K_{\mathrm{s}}}+\frac{T_{\mathrm{a}} \rho_{\mathrm{g}} \varphi}{T P_{\mathrm{a}}}+V_{\mathrm{l}} A\right] \frac{\partial p}{\partial t}} \\
& -\left[\rho_{\mathrm{g}}+\lambda P A\right] \frac{\partial \theta}{\partial t}+\nabla \cdot\left[-\frac{P k}{\mu} \nabla P\right]=Q_{\mathrm{s}} .
\end{aligned}
$$

Here, Langmuir's gas adsorption constant $A=\frac{V_{1} P_{1}\left(\rho_{\mathrm{g}} \rho_{\mathrm{c}}-\alpha \alpha_{\mathrm{sg}} \rho_{\mathrm{g}}\right) \exp (-\lambda \theta)}{\left(P_{1}+P\right)^{2}}$ his is the governing cross-coupled model for gas flow through a coal seam.

\section{Dynamic moisture loss equation}

The continuity equation for moisture transportation through the fracture network is (Pashin 2016)

$\frac{\partial w}{\partial t}+\nabla \cdot\left(\rho_{\mathrm{m}}+\rho_{\mathrm{v}} q_{\mathrm{g}}\right)=Q_{\mathrm{w}}$.

The first part on the left-hand side expresses the varying rate of moisture quantity, and the second part on the lefthand side represents the vapor diffusivity and mechanism related to advection.

The quantity of moisture in porous media is:

$w=\rho_{1} \theta+\rho_{\mathrm{v}} \varphi$.

Here, the first part on the right-hand side refers to the remaining water content in porous matrixes, while the second part on the right-hand side expresses the water vapor ctent in the porous medium (He et al. 2013).

A natural balance between the water vapor and the liquid water exists with the inclusion of relative humidity. Thus, the density of water vapor is

$\rho_{\mathrm{v}}=\rho_{\mathrm{v} 0} R H=\rho_{\mathrm{v} 0}\left[1-\exp \left(-k_{\theta} T \theta^{n}\right)\right]$.

The flowing gas carries moisture vapor associated with convective velocity that ds not depend on $\rho_{\mathrm{v} 0}$. After incorporating the equations as mentioned earlier (Eqs. 13-15), the governing equation for determining moisture loss in wet coal reservoir is

$$
\begin{aligned}
& \left\{\rho_{1}+\varphi \rho_{0}(1-R H) n k_{\theta} T \theta^{n-1}-\rho_{\mathrm{v}}(\alpha-\varphi)\left[-\alpha_{\mathrm{sg}} V_{1} \frac{\lambda P}{P_{1}+P} \exp (-\lambda \theta)+\frac{\varepsilon_{\theta l} \theta_{1}}{\left(\theta_{1}+\theta\right)^{2}}\right]\right\} \frac{\partial \theta}{\partial t} \\
& +\nabla \cdot\left[-D_{\mathrm{atm}} \cdot \beta \rho_{0}(1-R H) n k_{\theta} T \theta^{n-1} \nabla \theta\right]+\nabla \cdot\left[\rho_{\mathrm{v}}\left(-\frac{k}{\mu} \nabla P\right)\right] \\
& +\rho_{\mathrm{v}}(\alpha-\varphi)\left[\frac{1}{K_{\mathrm{s}}}-\alpha_{\mathrm{sg}} V_{1} \frac{P_{1}}{\left(P_{1}+P\right)^{2}} \exp (-\lambda \theta)\right] \frac{\partial P}{\partial t}+\rho_{\mathrm{v}}(\alpha-\varphi) \frac{\partial \varepsilon_{\mathrm{v}}}{\partial t}=Q_{\mathrm{w}} .
\end{aligned}
$$


After combining Eqs. (4), (6) and (15) into Eq. (16), we get the simple form as:

$$
\begin{aligned}
& \left\{\rho_{1}+\rho_{\mathrm{v}}(2 \varphi-\alpha)\left[-\alpha_{\mathrm{sg}} \varepsilon_{\mathrm{s}}+\varepsilon_{\theta}\right]\right\} \frac{\partial \theta}{\partial t} \\
& \quad+\nabla \cdot\left[\varphi_{0} \cdot \rho_{\mathrm{v}} \cdot \nabla \theta-\frac{\rho k}{\mu} \nabla P\right] \\
& \quad+\left\{\rho_{\mathrm{v}}(\alpha-\varphi)\left[\frac{1}{K_{\mathrm{s}}}-\varepsilon_{\mathrm{s}}+\alpha\right]\right\} \frac{\partial p}{\partial t}=Q_{\mathrm{w}} . \\
& {\left[\left\{\rho_{1}+\rho_{\mathrm{v}}(2 \varphi-\alpha)\left[-\alpha_{\mathrm{sg}} \varepsilon_{\mathrm{s}}+\varepsilon_{\theta}\right]\right\}\right.} \\
& \left.+\left\{\rho_{\mathrm{v}}(\alpha-\varphi)\left[\frac{1}{K_{\mathrm{s}}}-\varepsilon_{\mathrm{s}}+\alpha\right]\right\}\left(\frac{\partial p \rho_{1}}{\partial w}\right)\right] \frac{\partial \theta}{\partial t} \\
& +\nabla \cdot\left[\varphi_{0} \cdot \rho_{\mathrm{v}} \cdot \nabla \theta-\frac{\rho k}{\mu} \nabla P\right]=Q_{\mathrm{w}} .
\end{aligned}
$$

If the equilibrium pressure is independent of moisture content and space, the one-dimensional flow the model becomes

$\gamma \frac{\partial \theta}{\partial t}+\beta \frac{\partial^{2} \theta}{\partial x^{2}}=Q_{\mathrm{w}}$

where $\gamma=\left[\left\{\rho_{1}+\rho_{\mathrm{v}}(2 \varphi-\alpha)\left[-\alpha_{\mathrm{sg}} \varepsilon_{\mathrm{s}}+\varepsilon_{\theta}\right]\right\}+\left\{\rho_{\mathrm{v}}(\alpha-\varphi)\left[\frac{1}{K_{\mathrm{s}}}-\varepsilon_{\mathrm{s}}+\alpha\right]\right\}\right.$ $\left(D \rho_{1}\right), \beta=\varphi_{0} \cdot \rho_{\mathrm{v}} \frac{\rho k C}{\mu}, C$ and $D$ are the equilibrium pressure constant for space and moisture content. This is the governing cross-coupled model for moisture loss in a dynamic state.

$\mathrm{He}$, precisely, a set of nonlinear partial differential equations is provided for the gas flow equation and moisture loss equation with the first-order time and secondorder space. For the coal deformation model, the internal boundaries for the reservoir are at free stress conditions, while the external boundaries are made confined in the

\begin{tabular}{|c|c|c|c|}
\hline Variable & Parameter & Value & Unit \\
\hline E & Young's modulus of coal & 2713 & MPa \\
\hline$E_{\mathrm{s}}$ & Young's modulus of cola grains & 4070 & MPa \\
\hline$V$ & Poisson's ration of coal & 0.339 & \\
\hline$\theta_{0}$ & Initial value of moisture content & 0.08 & \\
\hline$\theta_{\mathrm{L}}$ & Langmuir strain constant for moisture sorption & 0.035 & \\
\hline$\varepsilon_{\Theta 1}$ & Volumetric strain constant for moisture sorption & 0.022 & \\
\hline$\rho_{\mathrm{c}}$ & Density of coal & 1250 & $\mathrm{~kg} \mathrm{~m}^{-3}$ \\
\hline$\rho_{\mathrm{g}}$ & Density of methane at standard condition & 0.717 & $\mathrm{~kg} \mathrm{~m}^{-3}$ \\
\hline$\rho_{1}$ & Density of liquid water & 1000 & $\mathrm{~kg} \mathrm{~m}^{-3}$ \\
\hline$\rho_{\mathrm{v} 0}$ & Density of saturated water vapor & 0.0396 & $\mathrm{~kg} \mathrm{~m}^{-3}$ \\
\hline$\alpha_{\mathrm{sg}}$ & Coefficient for sorption-induced volumetric strain & 0.06 & $\mathrm{~kg} \mathrm{~m}^{-3}$ \\
\hline$\varphi_{0}$ & Initial porosity of coal & 0.06 & \\
\hline$k_{0}$ & Initial permeability of coal & $10^{-15}$ & $\mathrm{~m}^{2}$ \\
\hline$k_{\theta}$ & Water evaporation constant & 2.71 & \\
\hline$M$ & Methane dynamic viscosity & $1.84 \times 10^{-5}$ & $\mathrm{~Pa} \mathrm{~s}$ \\
\hline$\Lambda$ & Adsorption decay coefficient & 14.4 & \\
\hline$V_{\mathrm{L}}$ & Langmuir volume constant for gas sorption & 0.043 & $\mathrm{~m}^{3} \mathrm{~kg}^{-1}$ \\
\hline$P_{\mathrm{L}}$ & Langmuir pressure constant for gas sorption & 1.57 & $\mathrm{MPa}$ \\
\hline$P_{0}$ & Initial value of gas pressure & 6 & MPa \\
\hline$P_{\mathrm{a}}$ & Pressure at standard condition & 0.103 & $\mathrm{MPa}$ \\
\hline$Q_{\mathrm{s}}$ & Gas source term & 0 & $\mathrm{Kg} \mathrm{m}^{-3} \mathrm{~s}^{-1}$ \\
\hline$Q_{\mathrm{w}}$ & Moisture source term & 0 & $\mathrm{Kg} \mathrm{m}^{-3} \mathrm{~s}^{-1}$ \\
\hline$T$ & Temperature of coal seam & 308 & $\mathrm{~K}$ \\
\hline$T_{\mathrm{a}}$ & Temperature at standard condition & 273 & $\mathrm{~K}$ \\
\hline$N$ & Material special factor & 2.25 & \\
\hline
\end{tabular}

Table 2 Boundary and initial conditions

Table 3 Parameters used in the governing models

\begin{tabular}{llll}
\hline Conditions & Stress or displacement & Gas pressure & Moisture content \\
\hline Initial condition & Zero & $6 \mathrm{MPa}$ & $8 \%$ \\
Internal boundary & Free & $0.1 \mathrm{MPa}$ & Zero \\
External boundary & Restrained & Zero & Zero \\
\hline
\end{tabular}


normal direction as placed in Table 2. Also, the parameters and factors used for these governing models are listed out in Table 3.

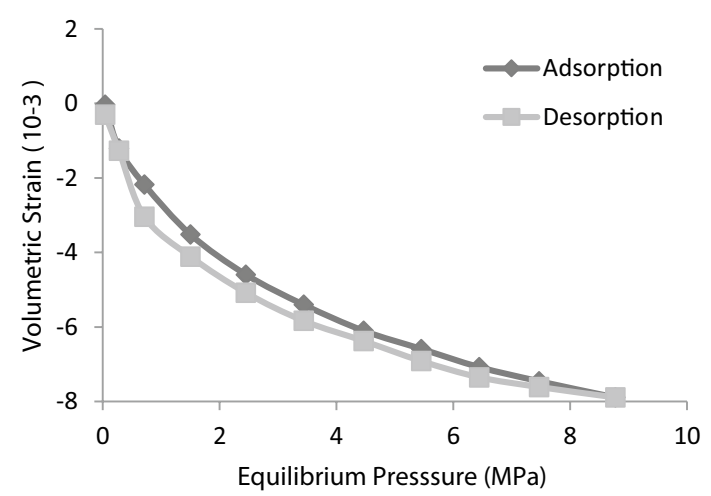

(a)

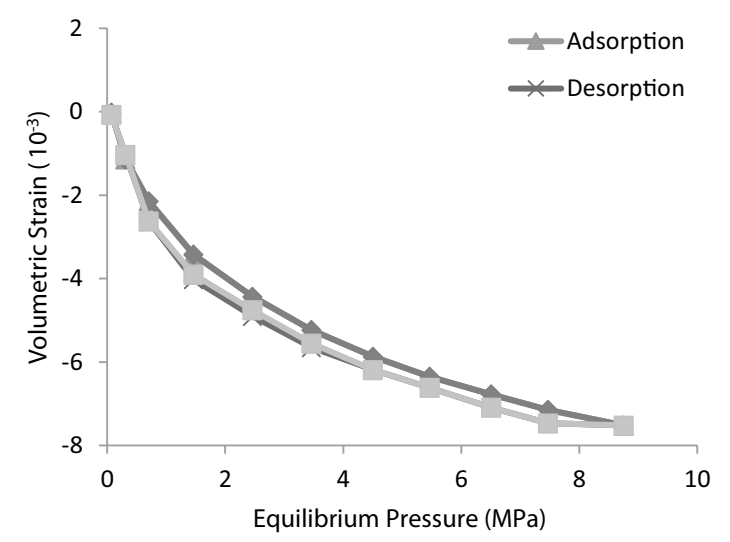

(c)

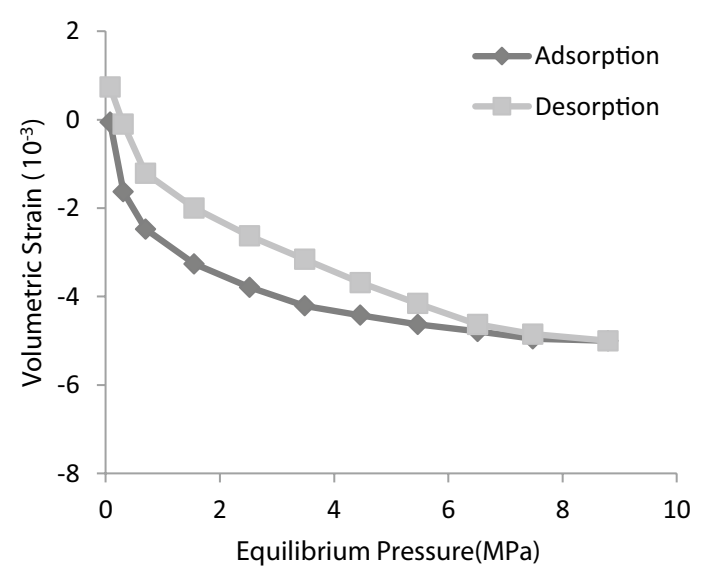

(e)

\section{Results and discussion}

In this study, one thing should be supposed based on the previous investigations from the geological science that

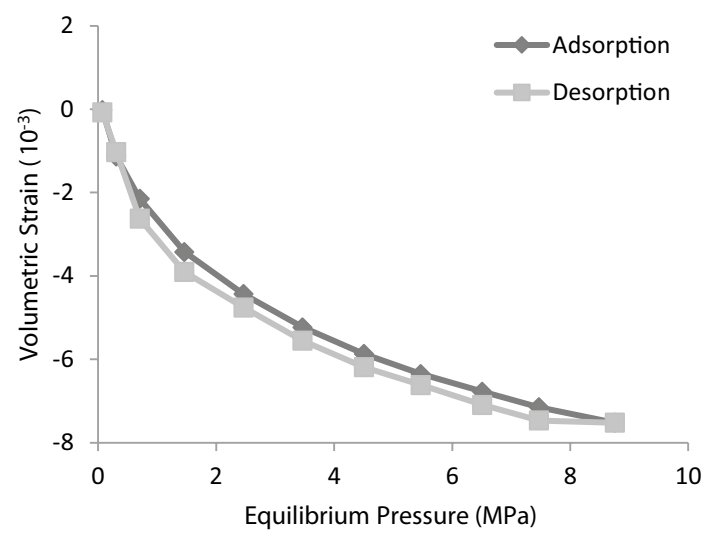

(b)

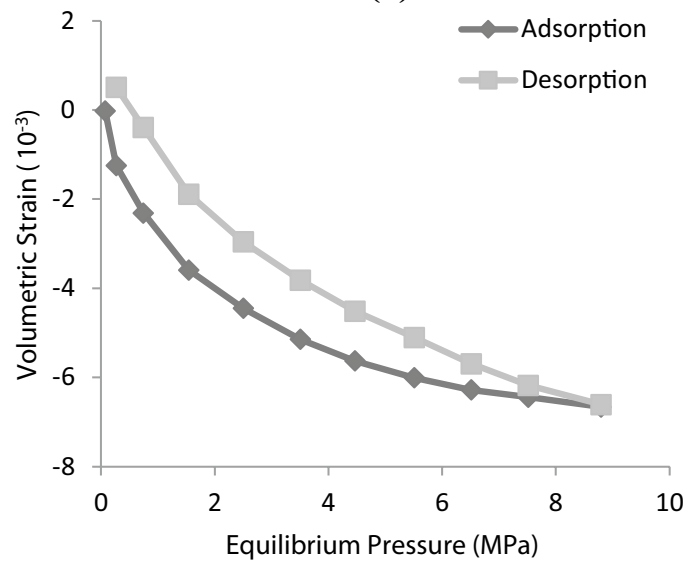

(d)

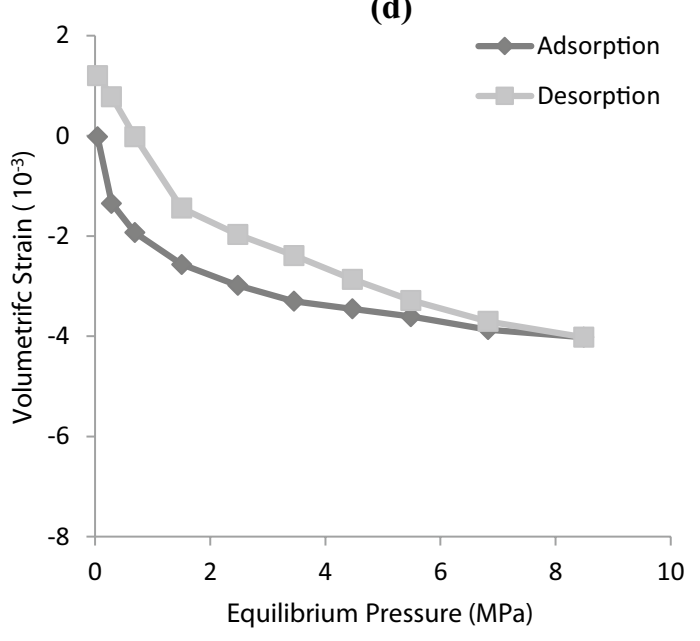

(f)

Fig. 2 Observed volumetric stains in different equilibrium pressures of coal particle based on various moisture contents at a $0.00 \%$, b $0.38 \%$, c $0.75 \%$, d $1.42 \%$, e $2.66 \%$, f $3.13 \%$ 
coal shrinkage and coal swelling deformations are positive strain and negative strain, respectively.

Below, the resultant analysis associated with the adsorption and desorption phenomena of volumetric strains at different equilibrium pressures is shown in Fig. 2. This analysis was done at various concentrations of moisture content. From this analysis, it has been forwarding to the decision that the volumetric strain reduces uniformly with the increasing equilibrium pressure at constant moisture content and temperature in the gas-induced adsorption and desorption processes (Fig. 2a-d). Though the decreasing rate of volumetric strain continuously decreases with the increasing equilibrium pressure, one time, it can reach a balance phase, where two variables will increase equally with each other. These trends of changing the adsorption curve under the influence of increasing moisture content are shown in Fig. 2e, f. Additionally, the deformation isotherms during methane adsorption and desorption processes are profoundly affected by the moisture content and pressure.

The fitting coefficients from the above curves shown in Fig. 2 are listed in Table 4, which are shown further in Fig. 3. It can be shown from Table 4 that the moisture content changes from 0 (zero) to $3.13 \%$, where the shrinkage and swelling strains change nearly by $30 \%$ and $60 \%$, respectively. This trend indicates that coal swelling strain is more significant in magnitude than coal shrinkage strain.

\section{Influence of moisture content on coal deformation}

In Fig. 3a, b, the swelling and shrinkage magnitudes of coal seams under different equilibrium pressures at various concentrations of moisture content are represented. These curves clearly show that moisture content keeps greater impacts on the methane-induced coal deformation retention of the coal matrix. For example, for a moisture concentration at $0.00,0.38,0.75,1.42,2.6$ and $3.13 \%$, the magnitudes of shrinkage strain are nearly $-7.10,-6.99$,
$-6.71,-5.91,-4.32$, and $-3.53 \times 10^{-3}$ and the magnitudes of swelling strain are nearly $-7.23,-6.98,-6.89$, $-6.30,4.77$, and $-3.77 \times 10^{-3}$, respectively, at a constant pressure of $7 \mathrm{MPa}$. These results show that the shrinkage deformation decreases nearly by 5.1, 5.3, 5.4, 6.3, 7.2, and $7.5 \%$ when the pressure reduces from 8 to $7 \mathrm{MPa}$. Again, it can be shown that the swelling deformation rises by 3.8 , 3.6, 6.2, 2.6, 1.4, and 1.4\%, when the pressure rises from 7 to $8 \mathrm{MPa}$, for a moisture concentration at $0.00,0.38,0.75$, $1.42,2.66$, and $3.13 \%$.

\section{Model validation}

Figure 4 shows the experimental results of Sander et al. (2014). The responses of the modified model (Fig. 3a, b) are compared with the data of Sander et al. (2014) to check out the reliability. From Fig. 4, at zero (0) equilibrium pressure, it can be shown that volumetric strain has a variation for different moisture contents. However, in Fig. 3, the volumetric strain is the same at zero equilibrium pressure for all moisture contents, which is considered more realistic. For intermediate equilibrium pressures, responses of both models are nearly identical for a fix moisture content. For example, for equilibrium pressure at $4 \mathrm{MPa}$, the volumetric strains for this study and Sander et al. are approximately 3.3 and 3.1 at a moisture content of $3.13 \%$. On the contrary, at high equilibrium pressure ( $8 \mathrm{MPa}$ ), this study shows more swelling than the findings of Sander et al. (2014). As, in a real scenario, more swelling is expected at higher equilibrium pressure, the response of the modified model is more realistic than the previous experiment. So, the relationship between volumetric strain vs. equilibrium pressure under various moisture contents exhibits that the model figures out the effects of moisture content more accurately on coal deformation curves under several characteristics of adsorption-desorption phenomena in the coal matrix by considering the gas sorption volumetric strain coefficient.

Table 4 Fitting coefficients

\begin{tabular}{|c|c|c|c|c|c|c|c|}
\hline \multirow{2}{*}{$\begin{array}{l}\text { Moisture } \\
\text { content, w } \\
(\%)\end{array}$} & \multicolumn{3}{|l|}{ Swelling } & \multicolumn{4}{|l|}{ Shrinkage } \\
\hline & $\begin{array}{l}\text { Ultimate } \\
\text { swelling strain } \\
\left(10^{-3}\right)\end{array}$ & $\begin{array}{l}\text { Relation parameter between } \\
\text { swelling strain and equilib- } \\
\text { rium pressure }\left(\mathrm{MPa}^{-1}\right)\end{array}$ & $\begin{array}{l}\text { Fitting } \\
\text { variances } \\
\left(R^{2}\right)\end{array}$ & $\begin{array}{l}\text { Ultimate } \\
\text { shrinkage strain } \\
\left(10^{-3}\right)\end{array}$ & $\begin{array}{l}\text { Relation parameter between } \\
\text { swelling strain and equilib- } \\
\text { rium pressure }\left(\mathrm{MPa}^{-1}\right)\end{array}$ & $\begin{array}{l}\text { Residual } \\
\text { strain } \\
\left(10^{-3}\right)\end{array}$ & $\begin{array}{l}\text { Fitting } \\
\text { variances } \\
\left(R^{2}\right)\end{array}$ \\
\hline 0 & -10.18 & 0.35 & 0.997 & -12.24 & 0.22 & 0.32 & 0.999 \\
\hline 0.38 & -9.67 & 0.37 & 0.997 & -12.22 & 0.22 & 0.51 & 0.999 \\
\hline 0.75 & -9.13 & 0.44 & 0.997 & -12.05 & 0.21 & 0.46 & 0.999 \\
\hline 1.42 & -7.88 & 0.57 & 0.998 & -12.2 & 0.18 & 0.89 & 0.997 \\
\hline 2.66 & -5.37 & 1.14 & 0.998 & -10.08 & 0.16 & 1.01 & 0.996 \\
\hline 3.13 & -4.26 & 1.11 & 0.993 & -8.69 & 0.17 & 1.19 & 0.994 \\
\hline
\end{tabular}


Fig. 3 Representing modified curves of volumetric strain of coal particles under various moisture contents: a swelling and $\mathbf{b}$ shrinkage

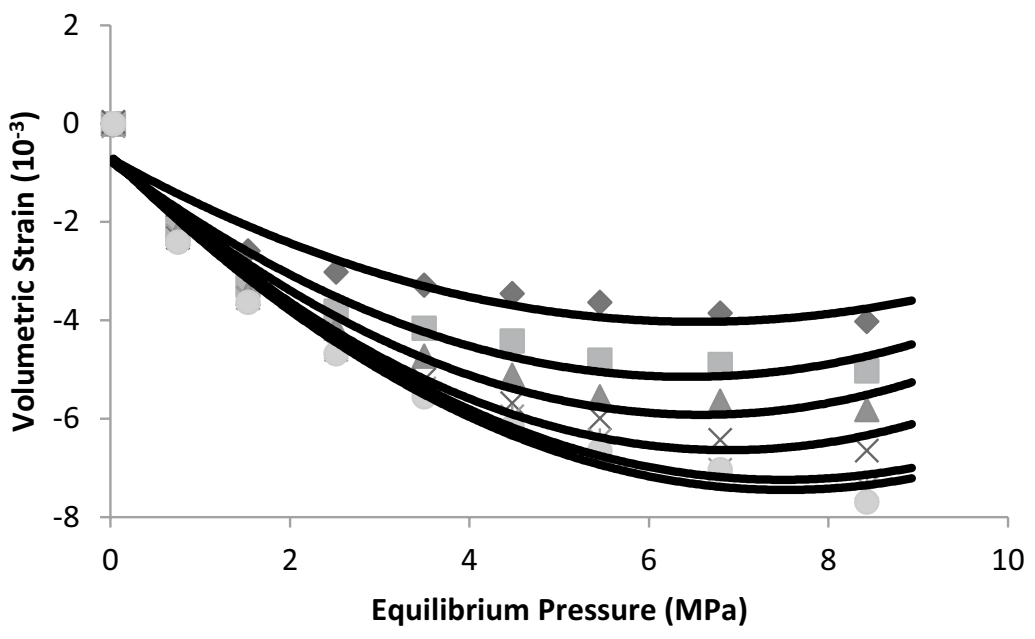

$3.13 \%$

$2.66 \%$

$\triangle 1.42 \%$

$\times 0.75 \%$

* $0.38 \%$

$0.00 \%$

(a)

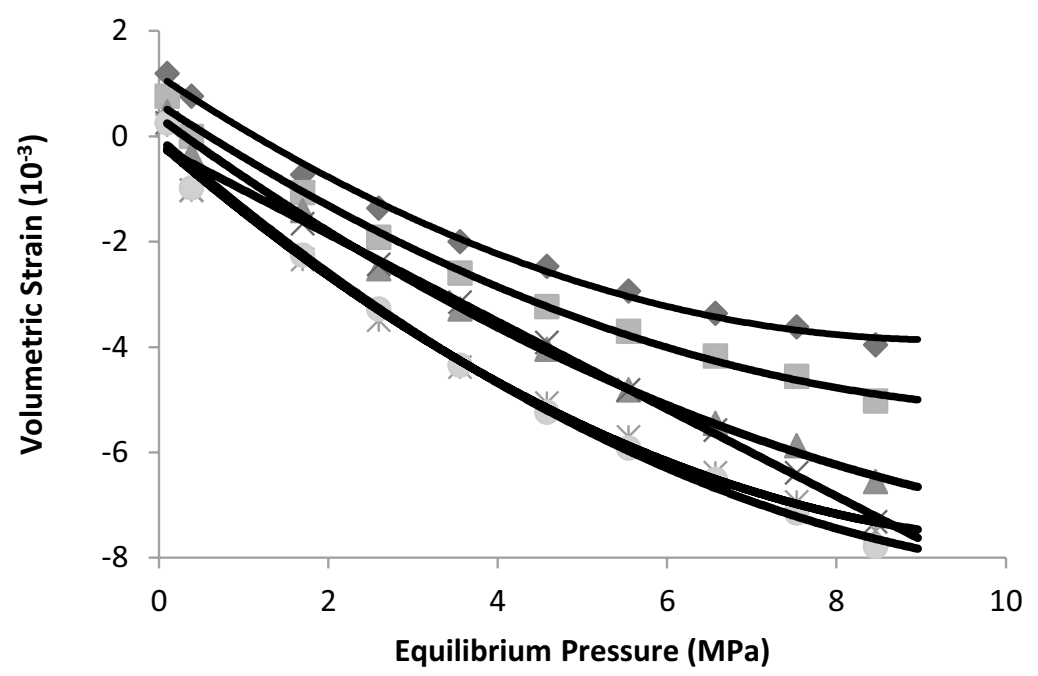

- $3.13 \%$

$2.66 \%$

$\triangle 1.42 \%$

$\times 0.75 \%$

$* 0.38 \%$

$0.00 \%$

(b)

\section{Hysteresis of swelling and shrinkage deformations}

Related to the adsorption and desorption isotherms exhibition, there exists a gap between the adsorption isotherms and desorption isotherms. This gap is called hysteresis. From Fig. 2, both the shrinkage deformation curves and swelling deformation curves show the isotherm hysteresis characteristics, though these hysteresis characteristics are slightly different in adsorption and desorption isotherms (Viete and Ranjith 2007). Therefore, the hysteresis characteristic is mainly focused in this study to differentiate the swelling deformation characteristics from the shrinkage deformation characteristics. To interpret this visual issue, a variable is employed to define the hysteresis rate as follows: $\omega=\frac{\varepsilon_{\mathrm{a}}-\varepsilon_{\mathrm{d}}}{\varepsilon_{\mathrm{a}}} \times 100 \%$

For several moisture contents, the hysteresis rates to different equilibrium moisture contents are shown in Fig. 5. From this figure, two following incidents are observed: (1) High equilibrium pressures correspond to a small hysteresis magnitude. That means the higher the equilibrium pressure would be, the lower the magnitude of hysteresis rate at fix moisture content. Differently, it can say that at a large magnitude of pressure, the hysteresis deformation curves for adsorption/desorption phenomena would be less significant. (2) In the case of constant equilibrium pressure, the hysteresis rate decreases along with the decrease in moisture content. Finally, it is more convenient coming to this decision that whatever it is adsorption hysteresis 
Fig. 4 The results of model validation. The line plots represent the model results: a swelling and $\mathbf{b}$ shrinkage

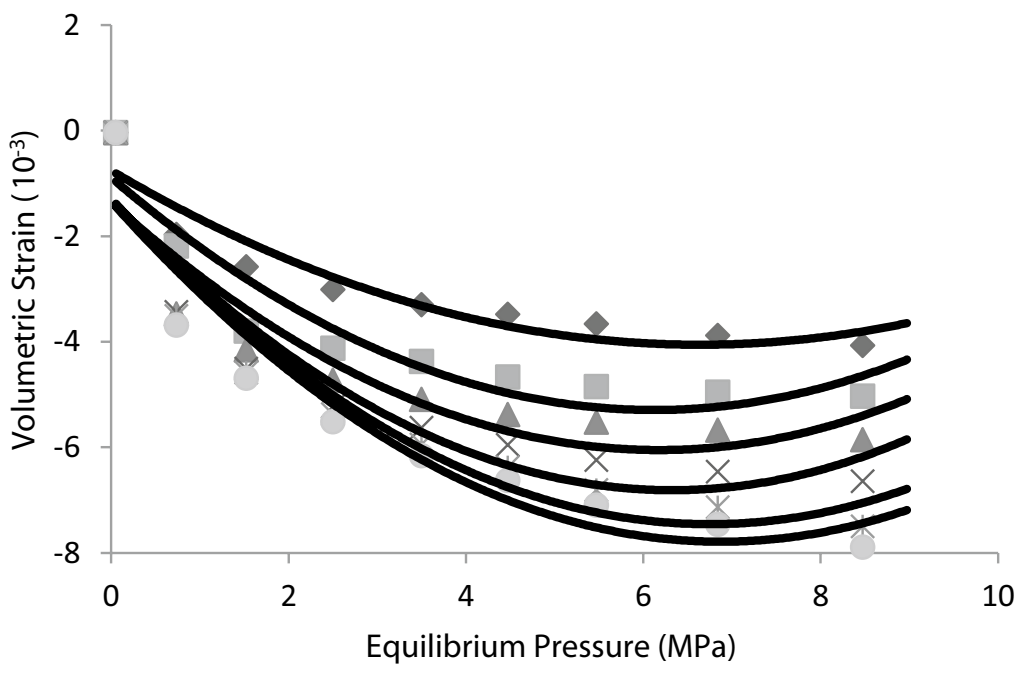

$\rightarrow 3.13 \%$

$2.66 \%$

$\triangle 1.42 \%$

$\times 0.75 \%$

* $0.38 \%$

$0.00 \%$

(a)

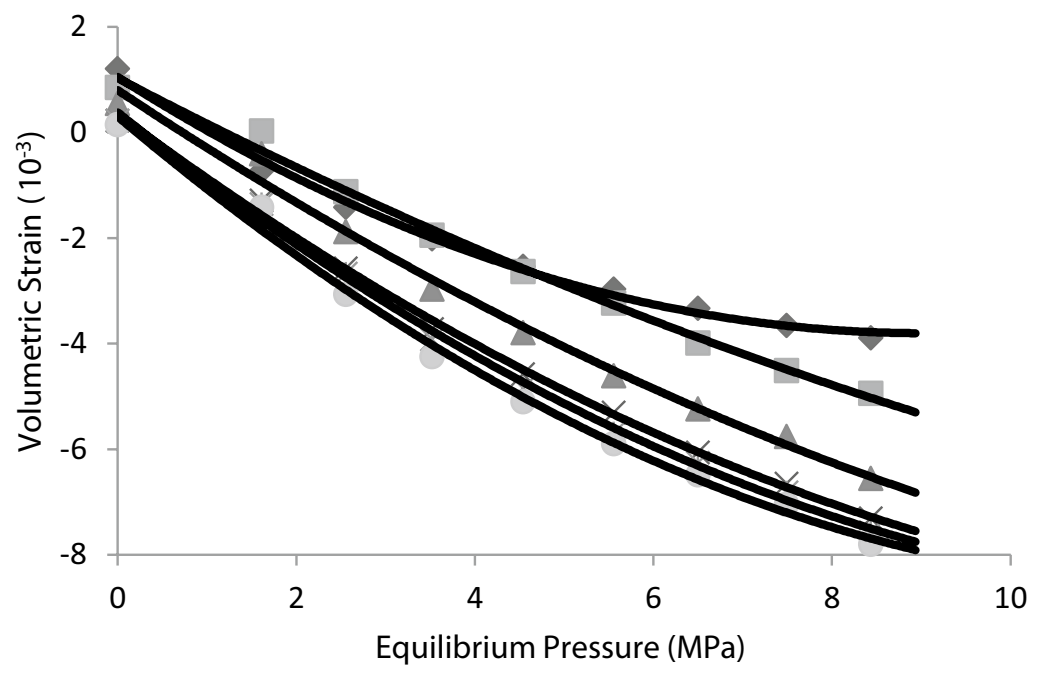

$3.13 \%$

$2.66 \%$

$\triangle 1.42 \%$

$\times 0.75 \%$

* $0.38 \%$

$0.00 \%$

(b)

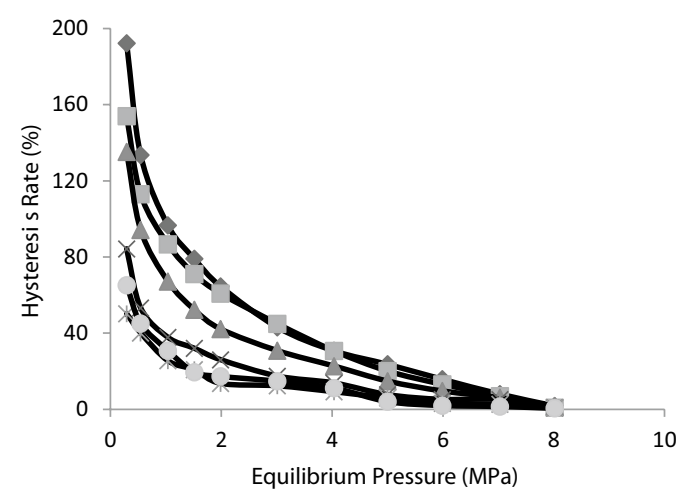

Fig. 5 Hysteresis rate under various moisture contents curve or desorption hysteresis curve, it must be affected significantly by the moisture content at a fix equilibrium pressure.

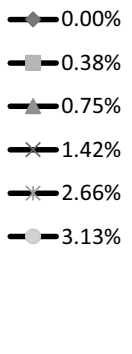

\section{Moisture effect on coal permeability}

Gas and moisture sorption-induced coal deformations are accountable for the influence of moisture content on permeability through the coal matrixes (Viete and Ranjith 2007). Firstly, moisture sorption-induced coal deformation model and gas sorption-induced coal deformation are combined, and afterward, a coal permeability model is designed. 
Fig. 6 Moisture sorptioninduced coal swelling strain with the Langmuir type of model

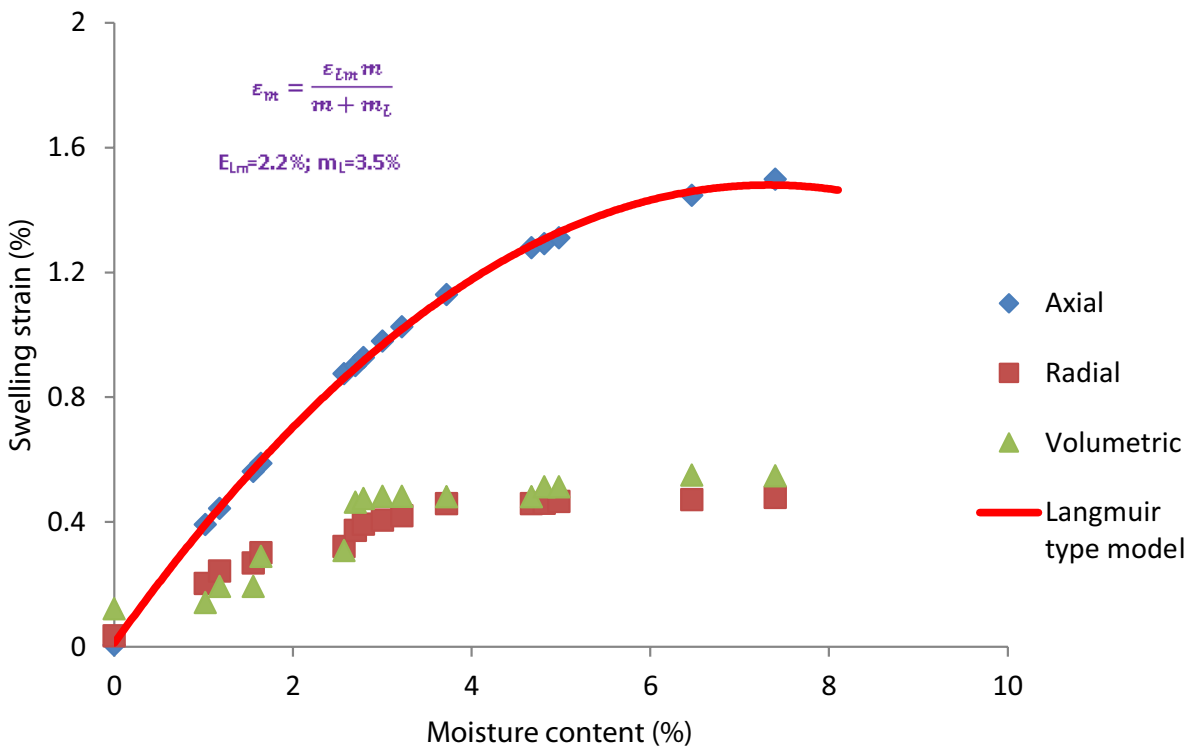

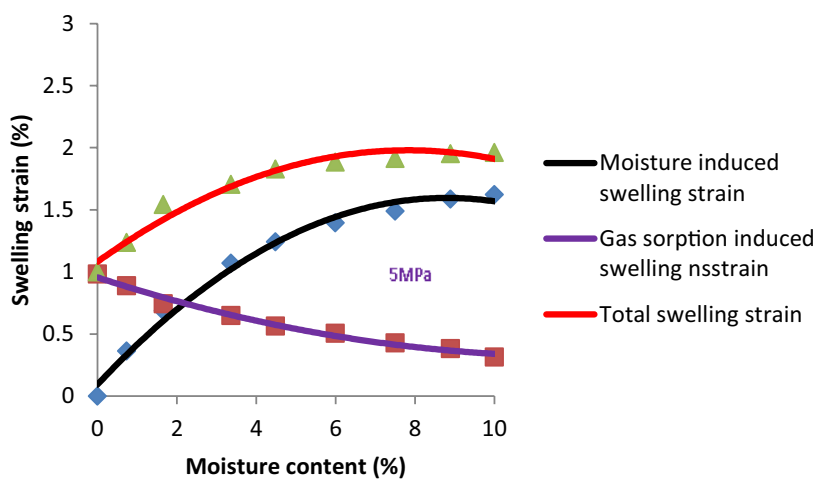

Fig. 7 Methane sorption-induced swelling strain of dry coal with the Langmuir type model

In Fig. 6, the Langmuir type model is matched with the moisture sorption initiated deformation model, which is expressed as follows:

$\varepsilon_{\mathrm{m}}=\frac{\varepsilon_{\mathrm{Lm}} m}{m+m_{\mathrm{L}}} \quad\left(0 \leq m \leq m_{\mathrm{c}}\right)$.

It is assumed for a fix moisture sorption that deformation of coal strain is usually corresponding to the content of gas adsorbed. Langmuir type equation is used for modeling the gas sorption-induced coal deformation $\left(\varepsilon_{\mathrm{s}}\right)$ and can be defined as (Sukla et al. 2013):

$\varepsilon_{\mathrm{s}}=\frac{\varepsilon_{\mathrm{L}} P}{P+P_{\varepsilon}}$.

Figure 7 represents a relationship between the methane sorption-induced coal swelling strain and the equilibrium

Fig. 8 Influence of moisture content on coal swelling strain at $5 \mathrm{MPa}$

gas pressure from matching with Eq. (22). Practically, moisture ithe coal matrix influences the gas adsorption efficiency both in high- or low-rank coals as expressed

$V_{\mathrm{w}}=V_{\mathrm{d}} \exp (-\lambda m) \quad\left(0 \leq m \leq m_{\mathrm{c}}\right)$.

The condition of gas sorption-induced coal deformation by assuming the influence of moisture content can be defined as follows:

$\varepsilon_{\mathrm{s}}=\frac{\varepsilon_{\mathrm{L}} P}{P+P_{\varepsilon}} \exp (-\lambda m) \quad\left(0 \leq m \leq m_{\mathrm{c}}\right)$.

Afterward, coal-swelling deformation incorporates both the moisture sorption-induced coal deformation and the gas sorption-induced coal deformation together, and hence, the equation for the total coal swelling deformation is derived as: 
Fig. 9 Variation of coal permeability as a function of gas pressure under the effect of moisture content

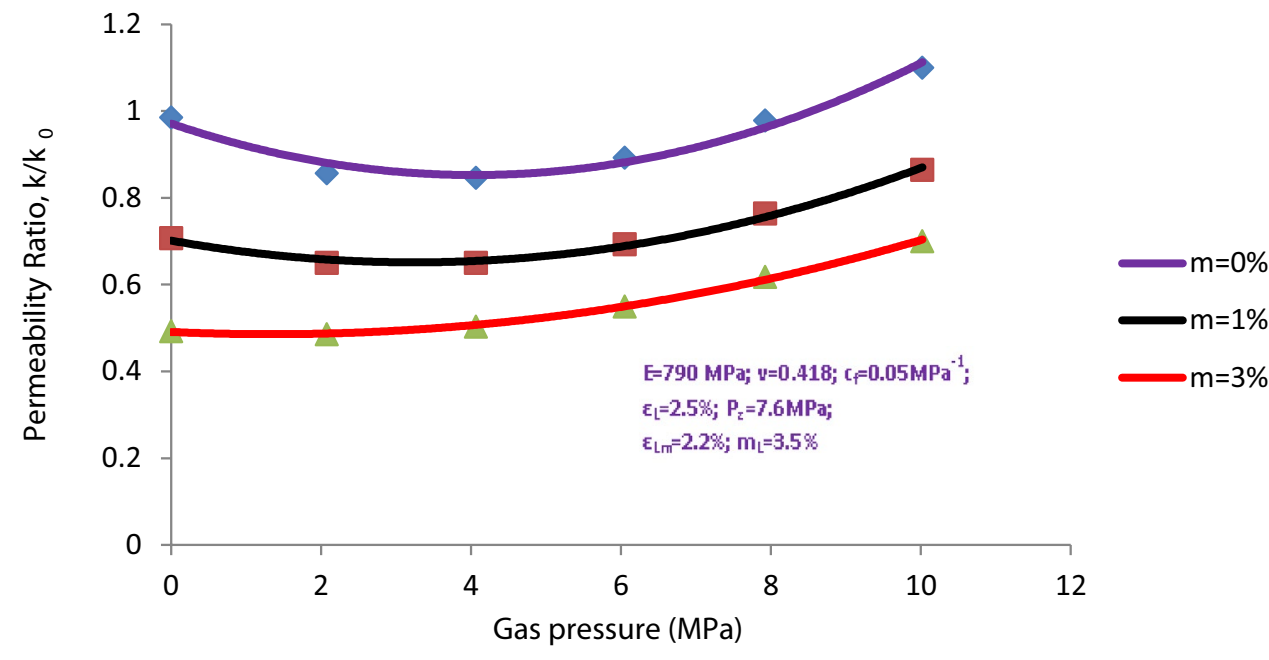

$\varepsilon_{\mathrm{sd}}=\varepsilon_{\mathrm{s}}+\varepsilon_{\mathrm{m}}=\frac{\varepsilon_{\mathrm{L}} P}{P+P_{\varepsilon}} \exp (-\lambda m)+\frac{\varepsilon_{\mathrm{Lm}} m}{m+m_{\mathrm{L}}} \quad\left(0 \leq m \leq m_{\mathrm{c}}\right)$.

After observing Figs. 6 and 7, and using Eq. (25), the parameters obtained from equilibrium gas pressure at $5 \mathrm{MPa}$ and different moisture contents are outlined in Fig. 8. The result exhibits that increasing moisture content decreases the gas sorption-induced coal deformation strain, but helps to increase the moisture sorption-induced coal deformation strain. However, for $2 \%$ adsorbed moisture content (at $5 \mathrm{MPA}$ ), the contributions from both moisture and gas sorptions are nearly the same on coal swelling strain. Nevertheless, in the case of 5\% adsorbed moisture content at the same equilibrium pressure, the ratio of contributions from both moisture and gas sorptions is nearly 2.6. (Each sorption contributes approximately 1.3 and 0.5 , respectively.) That means total coal swelling strain improves significantly owing to the increasing moisture-induced swelling strain at the time of moisture sorption in coal (Masoudian 2016; Pan and Connell 2012). Nevertheless, when the amount of moisture adsorption is higher than $5 \%$, then moisture sorption-induced coals swelling strain increases can be compared with the gas sorption-induced coal shrinkage decreases. The total coal deformation remains unchanged due to both moisture and gas sorption at that time. The modeling results indicate that moisture content at $5 \mathrm{MPa}$ for methane adsorption increases the overall coal strain. Still, this does not suggest in any way that other coal samples and gases will follow the exact behavior. In this way, the measurement of swelling and shrinkage strains has been analyzed for the moisture and gas adsorption corresponding to the amount of moisture vapor. One mostly applied model for determining the effect of moisture on coal permeability phenomena considered, known as the Shi and Durucan model as follows (Masoudian et al. 2013):

$\sigma-\sigma_{0}=-\frac{V}{1-V}\left(P-P_{0}\right)+\frac{E \cdot \varepsilon_{\mathrm{S}}}{3(1-V)}$.

This model has a relation with stress and can define the permeability as

$k_{f}=k_{f 0} \exp \left\{-3 c_{f}\left(\sigma-\sigma_{0}\right)\right\}$.

This yields:

$k_{f}=k_{f 0} \exp \left\{-c_{f}\left[\frac{-3 v\left(P-P_{0}\right)+E \cdot \varepsilon_{\mathrm{s}}}{(1-v)}\right]\right\}$.

It is not necessary that the pressure term used in Eq. (25) to be an equilibrium pressure for the gas adsorption in the matrix, while the pressure term used in Eq. (26) defines the gas pressure in the coal cleats. However, these two different pressure terms can behave in the same way when gas pressure reaches an equilibrium state.

In this study, instead of employing two kinds of pressure, only one equilibrium pressure is accepted for the gas adsorption in coal cleats to understand the effect of moisture content on permeability change. The change of permeability concerning the different levels of moisture content at different equilibrium pressures is measured based on Eqs. (26) and (28) and then shown in Fig. 9. The data used in this calculation are collected from the experiments (Pan and Connell 2012; Masoudian et al. 2013). The obtained results indicate that the shape of the permeability curve is also changed by the moisture content levels, not only by the magnitude. When gas pressure is changed from zero $(0)$ to around $4 \mathrm{Mpa}$, at that time, the coal swelling strain dominates to cause the coal permeability 
to decrease in dry coal. Nevertheless, permeability can bounce back with the gas pressure higher than $4 \mathrm{MPa}$ and keep a great contribution to make effective stress decrease, accountable for permeability change. However, permeability variation at high moisture condition and in the low-pressure region is highly deviated owing to the less gas sorption-induced strain, as can be observed from Fig. 9.

\section{Conclusion}

The moisture content adsorbed on the coal matrix influences the gas storage and gas flow characteristics in wet coal reservoirs. This study shows that the capacity of gas adsorption is declined, while the coal seam starts gaining liquid moisture content. Where previous studies were not able enough to find out the limitations related to the variation of characteristics gaps between adsorption and desorption isotherms, this paper has tried to show that how the moisture content can affect the isotherm curves under various equilibrium pressures using hysteresis rates. Moreover, the coal swelling strain model is employed to represent the phenomena that the moisture content increases can decrease the gas sorption-induced coal swelling strain and increase the moisture-induced coal swelling strain. It can also be observed from this study that the swelling/ shrinkage behaviors mostly rely on the coal gas-moisture interaction, to describe the overall behaviors of coal reservoirs. From the extending coal permeability model used in this study, we can reasonably come to this decision that to quantify the changes in moisture contents on coal seams is very significant in the evaluation of permeability change in wet reservoirs. This study will contribute significantly to the field of CBM production during gas recovery. These incorporating moisture effects on various directions of the reservoir properties will lead to more accurate gas recovery systems during gas production. At the same time, it will be evident that moisture content can change the above-mentioned distinctive parameters of the methane-adsorbed coal seams. However, the authors recommend the development of a model for moisture loss by considering the dynamic situation for the proper evaluation of a CBM production in wet conditions. Moreover, a dual fracture network in the coal matrix could be able to demonstrate the scenario more realistically. Finally, the production time must be taken for an extended period, as the water evaporation constant promotes the enhancement of permeability in wet coal seams.

\section{Compliance with ethical standards}

Conflict of interest The authors wish to confirm that there are no known conflicts of interest associated with this publication.

Open Access This article is licensed under a Creative Commons Attribution 4.0 International License, which permits use, sharing, adaptation, distribution and reproduction in any medium or format, as long as you give appropriate credit to the original author(s) and the source, provide a link to the Creative Commons licence, and indicate if changes were made. The images or other third party material in this article are included in the article's Creative Commons licence, unless indicated otherwise in a credit line to the material. If material is not included in the article's Creative Commons licence and your intended use is not permitted by statutory regulation or exceeds the permitted use, you will need to obtain permission directly from the copyright holder. To view a copy of this licence, visit http://creativecommons.org/licenses/by/4.0/.

\section{References}

Bae JS, Bhatia SK (2006) High-pressure adsorption of methane and carbon dioxide on coal. Energy Fuels 20(6):2599-2607

Bustin RM, Cui XJ, Chikatamarla L (2008) Impacts of volumetric strain on $\mathrm{CO}_{2}$ sequestration in coals and enhanced $\mathrm{CH}_{4}$ recovery. Am Assoc Pet Geol Bull 92(1):15-29

Chen Z, Liu J, Elsworth D, Connell LD, Pan Z (2010) Impact of $\mathrm{CO}_{2}$ injection and differential deformation on $\mathrm{CO}_{2}$ injectivity under in-situ stress conditions. Int J Coal Geol 81(2):97-108

Crosdale PJ, Moore TA, Mares TE (2008) Influence of moisture content and temperature on methane adsorption isotherm analysis for coals from a low-rank, biogenically-sourced gas reservoir. Int J Coal Geol 76(2):166-174

Cui X, Bustin RM (2005) Volumetric strain associated with methane desorption and its impact on coalbed gas production from deep coal seams. Am Assoc Petrol Geol Bull 89(9):1181-1202

Cui X, Bustin RM, Chikatamarla L (2007) Adsorption-induced coal swelling and stress, implications for methane production and acid gas sequestration into coal seams. J Geophys Res Solid Earth 112:102. https://doi.org/10.1029/2004JB003482

Day S, Fry R, Sakurovs R (2008) Swelling of Australian coals in supercritical $\mathrm{CO}_{2}$. Int J Coal Geol 74(1):41-52

Durucan S, Shi JQ (2009) Improving the $\mathrm{CO}_{2}$ well injectivity and enhanced coalbed methane production performance in coal seams. Int J Coal Geol 77(1):214-221

Evans DG, Allardice DJ (1978) Moisture in coal; in analytical methods for coal and coal products, vol 1. Academic Press, New York

Gilman A, Beckie R (2000) Flow of coalbed methane to a gallery. Tansp Porous Media 41(1):1-16

Gray I (1987) Reservoir engineering in coal seams. Part 1. The physical process of gas storage and movement in coal seams. SPE Reserv Eng SPE Pap 12514:28-34

He Q, Mohaghegh SD, Gholami V (2013) A field study on simulation of $\mathrm{CO}_{2}$ injection and ECBM production and prediction of $\mathrm{CO}_{2}$ storage capacity in unmineable coal seam. J Pet Eng. https://doi. org/10.1155/2013/803706 
Jamison VC, Kroth EM (1958) Available moisture storage capacity in relation to textural composition and organic matter content of several Missouri soils. Soil Sci Soc of Am J 22(3):189-192

Li X, Fang Z (2014) Current status and technical challenges of $\mathrm{CO}_{2}$ storage in coal seams and enhanced coalbed methane recovery: an overview. Int J Coal Sci Technol 1(1):93-102. https://doi. org/10.1007/s40789-014-0002-9

Masoudian MS (2016) Multipysics of carbon dioxide sequestration in coalbeds: a review with a focus on geomechanical characteristics of coal. J Rock Mech Geotech Eng 8:93-112. https://doi. org/10.1016/j.jrmge.2015.080.002

Masoudian MS, Airey DW, El-Zein A (2013) An experimental investigation on mechanical behviour of $\mathrm{CO}_{2}$ saturated coal specimens. Aust Geomech J 48(4):197-202

Mazzotti M, Pini R, Storti G (2009) Enhanced coalbed methane recovery. J Supercrit Fluids 47:619-627. https://doi.org/10.1016/j.supfl u.2008.08.013

Oudinot AY, Koperna GJ Jr, Philip ZG, Liu N, Heath JE, Wells A, Young GB, Wilson T (2011) CO2 injection performance in the Fruitland Coal Fairway, an Juan Basin: results of a filed pilot. SPE J 16:864-879. https://doi.org/10.2118/127073-PA

Palmer I, Mansoori J (1998) How permeability depends on stress and pore pressure in coalbeds: a new model. SPEREE 1(6):539-544

Pan Z, Connell LD (2007) A theoretical model for gas adsorptioninduced coal swelling. Int J Coal Geol 69(4):243-252. https://doi. org/10.1016/j.coal.2006.04.006

Pan Z, Connell LD (2012) Modeling permeability for coal reservoirs: A review of analytical models and testing data. Int $\mathrm{J}$ Coal Geol 92:1-44. https://doi.org/10.1016/j.coal.2011.12.009

Pan Z, Ye J, Zhou F, Tan Y, Connell L, Fan J (2017) $\mathrm{CO}_{2}$ storage in coal to enhance coalbed methane recovery: a review of filed experiments in China. Int Geol Rev. https://doi.org/10.1080/00206 814.2017.1373607

Pashin JC (2016) Geologic considerations for CO2 storage in coal. In: Singh TN (ed) Geologic carbon sequestration: understanding reservoir behavior. Berlin, Springer, pp 137-159

Perera MSA, Ranjith PG (2015) Enhanced coal bed methane recovery: using injection of nitrogen and carbon dioxide mixture. Handb Clean Energy Syst. https://doi.org/10.1002/9781118991978.hhces 218

Pini R, Ottinger S, Burlini L, Storti G, Mazzotti M (2009) Role of adsorption and swelling on the dynamics of gas injection in coal. J Geophys Res 114(B4):B04203. https://doi.org/10.1029/2008J B005961
Pini R, Storti G, Mazzotti M (2011) A model for enhanced coal bed metahne recovery aimed at carbon dioxide storage. Adsorption 17:889-900. https://doi.org/10.1007/s10450-011-9357-z

Sander R, Connell LD, Pan Z, Camilleri M, Heryanto D, Lupton N (2014) Core flooding experiments of $\mathrm{CO}_{2}$ enhanced coalbed methane recovery. Int J Coal Geol 17:113-125. https://doi. org/10.1016/j.coal.2014.06.007

Schepers K, Oudinot A, Ripepi N (2011) Enhanced gas recovery and $\mathrm{CO} 2$ storage in coal bed methane reservoirs: optimized injected gas composition for mature basins of various coal rank. AAPG Eastern Section Meeting, Washington

Scott AR (2002) Hydrologic factors affecting gas content distribution in coal beds. Int J Coal Geol 50:363-387

Shao SWS, Ranjith PG, Viete DR, Jaysinge D (2012) Carbon dioxide storage in coal: reconstituted coal as a structurally homogeneous substitute for coal. Int J Coal Prep Util 32:265-275

Shi JQ, Durucan S (2004) Drawdown induced changes in permeability of coalbeds: a new interpretation of the reservoir response to primary recovery. Transp Porouss Med 56:1-16

Smith DM, Williams FL (1984) Diffusional effects in the recovery of methane from coalbeds. SPE J 24:529-535

Sukla R, Ranjith PG, Choi SK (2013) Mechanical behavior of reservoir rock under brine saturation. Rock Mech Rock Eng 46:83-93

Viete DR, Ranjith PG (2007) The mechanical behavior of coal with respect to $\mathrm{CO}_{2}$ sequestration in deep coal seams. Fuel 86:2667-2671

Vishal V, Ranjith PG, Singh TN (2013) $\mathrm{CO}_{2}$ permeability of Indian bituminous coals: implications for carbon sequestration. Int J Coal Geol 105:36-47

Wang GD, Ren T, Wang K, Zhou AT (2014) Improved apparent permeability models of gas flow in coal with Klinkenberg effect. Fuel 128:53-61

White CM, Smith DH, Joness KL, Goodman AL, Jikich SA (2005) Sequestration of carbon dioxide in coal with enhanced coalbed methane recovery-a review. Energy Fuels 19(3):659-724. https ://doi.org/10.1021/ef040047w

Yamaguchi S, Ohga K, Fujioka M, Nako M (2006) Field test and history matching of the $\mathrm{CO}_{2}$ sequestration project in coal seams in Japan. Int J Soc Mater Eng Resour 13(2):64-69. https://doi. org/10.5188/ijsmer.13.64

Publisher's Note Springer Nature remains neutral with regard to jurisdictional claims in published maps and institutional affiliations. 